Abstract

\title{
piRNA Function in Insect Oogenesis
}

\section{Andrea Lancho-Exposito 1, Oscar Paniello ${ }^{1}$, Josep Bau ${ }^{2}$ and Maria-Dolors Piulachs 1,*}

Citation: Lancho-Exposito, A.; Paniello, O.; Bau, J.; Piulachs, M.D. piRNA Function in Insect Oogenesis, in Proceedings of the 1st International Electronic Conference on Entomology, 1-15 July 2021, MDPI: Basel, Switzerland, doi:10.3390/IECE10574

Published: 2 July 2021

Publisher's Note: MDPI stays neutral with regard to jurisdictional claims in published maps and institutional affiliations.

Copyright: (c) 2021 by the authors. Submitted for possible open access publication under the terms and conditions of the Creative Commons Attribution (CC BY) license (http://creativecommons.org/licenses /by/4.0/).
${ }^{1}$ Institute of Evolutionary Biology (CSIC- Universitat Pompeu Fabra). Barcelona. Spain

2 Department of Biosciences, University of Vic - Central University of Catalonia, Vic, Barcelona, Spain

* Correspondence: mdolors.piulachs@ibe.upf-csic.es

+ Presented at the 1st International Electronic Conference on Entomology (IECE 2021), 1-15 July 2021; Available online: https://iece.sciforum.net/.

\begin{abstract}
Piwi-interacting RNAs (piRNAs) is a class of small non-coding RNAs (sncRNAs) of 28-29 nucleotides in length, poorly conserved across species. The first function associated with the piRNAs was the repression of transposable elements (TE) expression. But, since that time, more piRNA functions have been discovered. They are not only repressors of TEs but also act as regulators of the expression of some mRNAs. A better understanding of the role of piRNAs is required and we focused our attention on their role in insect oogenesis. Using the cockroach Blattella germanica as experimental model, we studied the expression pattern of a piRNA specific to this cockroach (Bger_piRNA-40669). We analyzed the Bger_piRNA-40669 expression in adult ovaries during the first gonadotropic cycle, and to further study its function, we upregulated its expression using a chemically synthesized piRNA 2'-O-methylated at the 3' end and phosphorylated at the 5' end. We found that an increase of Bger_piRNA-40669 in young adult females determines a shortening of the gonadotropic cycle, although embryogenesis was not affected. Moreover, our results show that Bger_piRNA-40669 has a specific function regarding oocyte development in B. germanica.
\end{abstract}

Keywords: cockroach; Blattella germanica; oogenesis; small RNAs 